\title{
NOTE
}

\section{In Vitro Effect of LH-Releasing Factor on the Content of Cyclic Cytidine 3' 5' Monophosphate (c-CMP) in the Rat Anterior Pituitary}

\author{
Masayoshi ARISAWA, Tsunehisa MAKINO, Horyo LIN, \\ TORANOSHIN OHNO AND RIHACHI IIZUKA \\ Department of Obstetrics and Gynecology School of Medicine, \\ Keio University, Shinjuku-ku, Tokyo.
}

\begin{abstract}
Abstruct
The effect of LH-RF on pituitary content of cyclic cytidine $3^{\prime} 5^{\prime}$ monophosphate (c-CMP), one of the newly detected cyclic nucleotides, was examined by the RIA procedure. In results showed that the pituitary content of c-CMP was lower than in various other organs of the rat. When incubated in vitro in the presence of $0.5 \mathrm{ng} \mathrm{LH}-\mathrm{RF} / \mathrm{ml}$ incubation medium, c-CMP content of the anterior pituitaries was reduced slightly, but the difference was not statistically significant when compared with the controls. No difference in c-CMP content was observed between the controls and the $5 \mathrm{ng} \mathrm{LH}-\mathrm{RF} / \mathrm{m} l$ group. C-CMP content in the rat anterior pituitary tissue did not change significantly during an in vitro time-course study $(5,15$, and $30 \mathrm{~min}$.) in the presence of $5 \mathrm{ng} \mathrm{LH}-\mathrm{RF} / \mathrm{ml}$. In contrast, c-AMP content of the pituitary was significantly $(\mathrm{P}<0.05)$ elevated by the stimulation of $5 \mathrm{ng}$ of $\mathrm{LH}-\mathrm{RF} / \mathrm{m} l$ at a 15 minutes of incubation. These data suggest that c-CMP content, unlike c-AMP, might not be changed significantly by hypothalamic gonadotropin releasing hormone.
\end{abstract}

Cyclic cytidine $3^{\prime} 5^{\prime}$ monophosphate (cCMP) was first identified in mouse leukemia cells by Block in 1974 . He also reported (1974) that c-CMP had the growth stimulatory effect of leukemia cells although c-AMP inhibited the growth of leukemia cells.

It has recently been suggested (Shoji et al., 1978) that c-CMP may play a regulatory role in cell metabolism. In 1978, Cailla, et al. first reported an RIA procedure for c-CMP and measured the concentration of C-CMP in rat tissues using this system. Although we had already examined the role of c-AMP as related to the mechanism of the action of LH$\mathrm{RF}$, it was also reported that c-GMP might play a regulatory role in the mechanism of

Received April 3, 1981 this hormone (Nakano et al., 1978), suggesting that various kinds of cyclic nucleotides may play a regulatory role in the mechanism of the action of LH-RF. The aim of this study is to investigate the change in the pituitary content of c-CMP in the mechanism of action of LH-RF in comparison with cAMP, which could be the 2nd messenger of LH-RF in the anterior pituitary gland.

\section{Materials and Methods}

Anterior pituitaries were obtained from male Sprague-Dowley rats (weighing 200 to 220 grams) immediately after decapitation. The pituitaries were weighed, hemisected and incubated in $2 \mathrm{ml}$ of tissue culture medium 199 (Difco), which had been previously saturated with $95 \% \mathrm{O}_{2}$ and $5 \% \mathrm{CO}_{2}$, in a Dubnoff metabolic incubator at $37^{\circ} \mathrm{C}$ with constant shaking at 
60 cycles per minute. Ten pituitary halves were incubated in two to three flasks. Pituitary contents of cyclic nucleotides were expressed as the mean value of duplicates. In all experiments, the pituitaries were preincubated for 30 minutes in control medium and then transferred to either control medium or medium that contained LH-RF. Synthetic LH-RF was added to the incubation medium in concentrations of 0.5 and $5 \mathrm{ng} / \mathrm{ml}$. After various periods of incubation, the pituitaries were homogenized with $2 \mathrm{ml}$ of $5 \%$ trichloacetic acid and centrifuged. The trichloacetic acid of the supernatant was extracted three times with three volumes of ethylether $\left(\mathrm{H}_{2} \mathrm{O}\right.$ saturated) and the supernatant was lyophilized. The lyophilized samples were diluted with $100 \mu \mathrm{l}$ of $0.05 \mathrm{M}$ phosphate buffer saline and c-CMP in the diluted mixture was succinylated with a dioxane-triethylamine mixture containing succinic anhydride. Approximately $70 \%$ of the cCMP of samples are converted to succinyl-c-CMP. Succinyl-c-CMP was measured by means of a sensitive RIA procedure reported by Satoh et al. (1980). Pituitary c-AMP content was assayed as described earlier, (Makino et al. 1973). Other organs of the rat were frozen with liquid nitrogen immediately after decapitation and homogenized thereafter with $2 \mathrm{ml}$ of $5 \%$ trichloacetic acid prior to c-CMP estimation by the same RIA procedure as described above.

\section{Results and Discussion}

The levels of c-CMP in various rat tissues are listed in Table 1. They are similar to the levels of c-CMP already reported (Murphy et al., 1979) (Cailla et al., 1978). The distribution of c-CMP in the rat brain is shown in Table 2. These data indicate that the c-CMP concentrations in the rat brain are lower than those of other organs. The effects of synthetic LH-RF on c-CMP content of rat anterior pituitaries at 15 minutes of incubation were examined. Pituitary c-CMP content (mean \pm S.D.) in the presence of $0.5 \mathrm{ng} \mathrm{LH}-\mathrm{RF} / \mathrm{ml}$ $(0.85 \pm 0.27 \mathrm{f}$ moles $/ \mathrm{mg})$ was lower than that of the control $(1.38 \pm 0.27 \mathrm{f}$ moles $/ \mathrm{mg})$, but it was not statistically significant $(\mathrm{P}>0.05)$. However, the content of c-CMP at $5 \mathrm{ng}$ of LH-RF/ml was virtually unaltered as compared to that of the control $(1.20 \pm 0.24 v s$. $0.98 \pm 0.31 \mathrm{f} \mathrm{moles} / \mathrm{mg}$ ). During the time course study, no significant change in the pituitary c-CMP content was observed at 5, 15,
Table 1. Cyclic-CMP Concentration in Rat Tissues

\begin{tabular}{lll}
\hline \hline \multicolumn{1}{c}{ Tissue } & \multicolumn{2}{c}{$\begin{array}{c}\text { c-CMP f moles/mg } \\
\text { wet weight } \\
\text { (mean } \pm \text { s.D.) }\end{array}$} \\
\hline Lung & $1.10 \pm 0.26$ & $(5)^{\mathrm{a})}$ \\
Heart & $1.10 \pm 0.58$ & $(5)$ \\
Liver & $1.34 \pm 0.52$ & $(5)$ \\
Intestine & $0.96 \pm 0.35$ & $(5)$ \\
Spleen & $2.29 \pm 1.26$ & $(5)$ \\
Kidney & $1.36 \pm 0.48$ & $(5)$ \\
Adrenal gland & $1.01 \pm 0.34$ & $(5)$ \\
Uterus & $1.08 \pm 0.30$ & $(5)$ \\
Ovary & $1.14 \pm 0.34$ & $(5)$ \\
\hline
\end{tabular}

a) number of samples

Table 2. Cyclic-CMP Concentration in the Rat Brain

\begin{tabular}{lll}
\hline \multicolumn{1}{c}{ Brain } & $\begin{array}{c}\text { c-CMP f moles/mg } \\
\text { wet weight } \\
\text { (Mean } \pm \text { S.D.) }\end{array}$ \\
\hline Cortex & $0.68 \pm 0.18$ & $\left.(6)^{\mathrm{a}}\right)$ \\
Limbic System & $0.79 \pm 0.32$ & $(6)$ \\
Hypothalamus & $0.49 \pm 0.14$ & $(6)$ \\
Pituitary Gland & $0.97 \pm 0.26$ & $(4)$ \\
Cerebellum & $0.77 \pm 0.26$ & $(6)$ \\
\hline
\end{tabular}

a) number of samples

and 30 minutes of incubation in the presence of $5 \mathrm{ng} \mathrm{LH}-\mathrm{RF}$ as compared to the control, as shown in Figure 1, though the content of c-CMP decreased slightly, but not significantly, $(P>0.05)$ at 5 minutes of incubation. In contrast, c-AMP content of the pituitary was significantly $(\mathrm{P}<0.05)$ elevated by stimulating with $5 \mathrm{ng}$ of $\mathrm{LH}-\mathrm{RF} / \mathrm{ml}$ at 5 minutes of incubation, as demonstrated in Figure 2. We previously reported that the release of $\mathrm{LH}$ and FSH in vitro from the rat anterior pituitary in response to synthetic LH-RF could be mediated by the adenyl cyclase-cyclic AMP pathway (Makino, 1973). But it was recently reported that c-GMP also might play a regulatory role in the mechanism of LH-RF (Nakano et al., 1978). It is possible that various kinds of cylic nucleotides may play a regulatory role in the release of gonadotropins in response to LH-RF. In this study, the possibility of the role of c-CMP in terms of the 


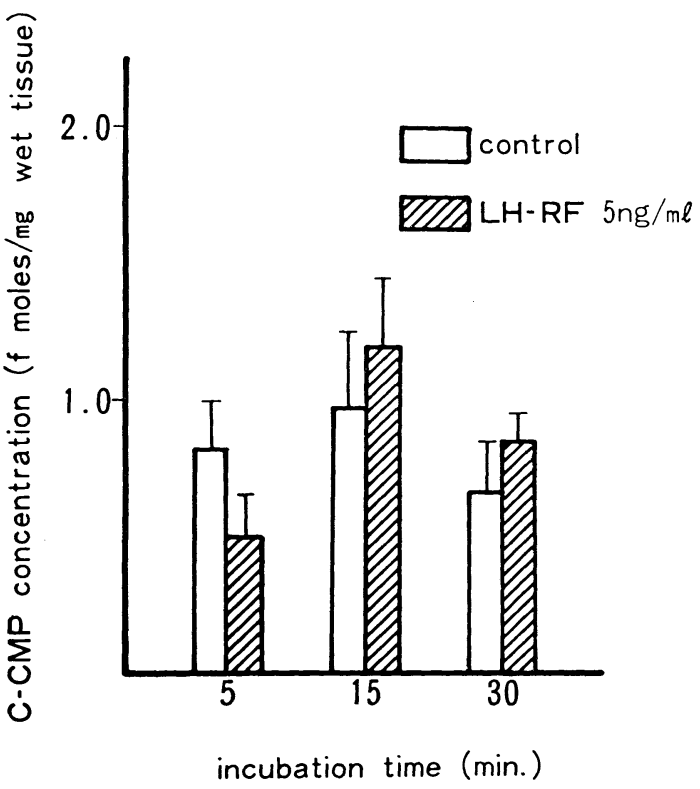

Fig. 1. Time course study of effect of LH-RF on cCMP concentration in rat anterior pituitary. Ten pituitary halves were incubated in two to three flasks. Donor pituitary halves were preincubated for 30 minutes and then transferred to control medium TC199 or medium containing $5 \mathrm{ng}$ of LH$\mathrm{RF} / \mathrm{ml}$. Incubations were continued for 5 to 30 minutes. After incubation, c-CMP content of the pituitary halves was assayed by RIA. The values obtained are given as mean \pm S.D. (f moles/mg wet tissue)

mechanism associated with the action of LHRF was examined. It is of interest that the pituitary content of c-CMP was not altered by stimulating with LH-RF while a significant elevation of c-AMP concentration was observed. It is suggested that, if an effect of a hormone is mediated by a cylic nucleotide, then it should satisfy all of the criteria of the second messenger theory (Sutherland et al., 1968). Since only $70 \%$ of the c-CMP is converted to succinyl-c-CMP and c-CMP content of rat brain, as well as other tissues, this is quite low, as shown in Table 1 and 2, and it may not be possible to draw definite conclusions from the present study. However, the present data suggest that, though

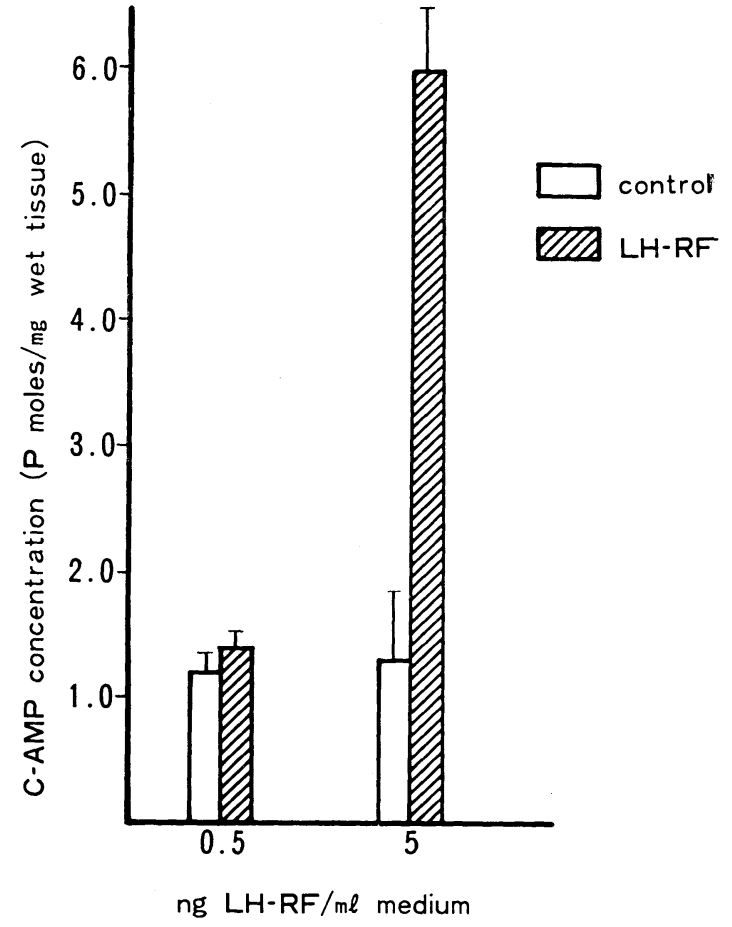

Fig. 2. Dose-response effect of LH-RF on c-AMP concentration in rat anterior pituitary. Four pituitary halves were incubated in four flasks. Pituitary halves were incubated for 5 minutes in $2 \mathrm{ml}$ of TC199 with 0.5 and $5 \mathrm{ng}$ of $\mathrm{LH}-\mathrm{RF} / \mathrm{ml}$ after 30 minutes of preincubation. After incubation, the c-AMP content of pituitary halves was assayed by RIA. The values obtained are given as mean \pm S.D. (f moles/ mg wet tissue)

synthetic LH-RF, instead of endogenous LH$\mathrm{RF}$, was used in this study, c-CMP in the anterior pituitary might not be changed by hypothalamic LH-RF.

\section{Acknowledgements}

The authors wish to thank Dr. T. Satoh, Research Laboratory, Yamasa Shoyu Co., Ltd. for the gift of c-CMP assay reagents and for helpful discussions and suggestions. This study is supported in part by the Grant from Mitsubishikasei Center Institute.

Synthetic LH-RF was a gift from Sankyo Pharmaceutical Co., Ltd. 


\section{References}

Bloch, A. (1974). Cytidine 3',5'-monophosphate (Cyclic-CMP) I. Isolation from extracts of leukemia L-1210 cells. Biochem. Biophys. Res. Commun. 58, 652.

Bloch, A., G. Dutschman, and R. Maue (1974). Cytidine 3',5'-monophosphate (Cyclic-CMP) II. Initiation of leukemia L-1210 cell growth in vitro. Biochem. Biophys. Res. Commun. 59, 955.

Cailla, H. L., D. Roux, M. Dellage, and C. Goridis (1978). Radioimmunological identification and measurment of cytidine $3^{\prime}, 5^{\prime}$-monophosphate in rat tissues. Biochem. Biophys. Res. Commun., 85. 1503.

Cech, S. Y. and L. J. Ignarro (1977). Cytidine 3',5'monophosphate (Cyclic-CMP) formation in mammalian tissues. Science, 198, 1063.

Cech, S. Y. and L. J. Ignarro (1978). Cytidine 3',5'monophosphate (Cyclic-CMP) formation by homogenates of mous liver. Biochem. Biophys. Res. Commun., 80, 199.

Gaion, R. M. and G. Krishna (1979). Cytidylate cyclase: the product isolated by the method of Cech and Ignorro is not cytidine $3^{\prime}, 5^{\prime}$-monophosphate. Biochem. Biophys. Res. Commun., 86, 105.

Kuo, J. F., N. L. Brokett, M. Shoji, and J. Tse (1975). Cytidine $3^{\prime}, 5^{\prime}$-monophosphate phosphodiesterase in mammalian tissues. J. Biol. Chem., 253, 2518.

Makino, T. (1973). Study on the intracellular mechanism of LH release in the anterior pituitary. Am. J. Obstet. Gynecol., 115, 606.

Murphy, B. E. and J. E. Stone (1978). Radioimmunoassay (RIA) for cytosine $3^{\prime}, 5^{\prime}$-monophosphate (CCMP). Pharmacologist, 20, 232.

Murphy, B. E. and J. E. Stone (1979). Radioimmunoassay of cytidine $3^{\prime}, 5^{\prime}$-monophosphate (C-CMP) I. Development of the assay. Biochem. Biophys. Res. Commun., 89, 122.

Nakano, H., C. P. Fawcett, F. Kimura, and S. M. McCann (1978). Evidence for the involvement of guanosine $3^{\prime}, 5^{\prime}$-cyclic monophosphate in the regulation of gonadotropin release. Endoc., 103, 1527.

Sato, T., A. Kuninaka and H. Yoshino (1980). Abstract of The 53rd General Meeting of Japanese Pharmacological Society.

Shoji, M., N. L. Brackett, D. M. Helfman, H. P. Morris, and J. F. Kuo (1978). Decreased activity of cytidine $3^{\prime}, 5^{\prime}$-monophosphate (Cylic-CMP) phosphodiesterase in the fast-growing morris hepatoma 3924A, but not in the slow-growing morris hepatoma 9618A. Biochem. Biophys. Res. Commun., 83, 1140.

Sutherland, E. W., G. A. Robinson and R. W. Butcher (1968). Some aspects of the biological role of adenosine $3^{\prime}, 5^{\prime}$-monophosphate (Cyclic-AMP). Circulation, 37, 279. 